These examples show that the processes of evolution in astronomy are not always imperceptibly slow. The outermost layers of stellar atmospheres are extremely unstable formations which often undergo marked changes in a few weeks or even days. Apparently these formations are supported by a delicate balance of three forces: gravity downward, towards the centre of the star, radiation pressure from the brilliant. continuous spectrum of the photosphere directed outward, and radiation pressure within the Lyman alpha line of hydrogen from the tenuous shell. This latter force is directed inward in the deeper regions of the atmospheric shell, and outward in the outermost regions. A small disturbance of the balance of these forces causes the entire structure to collapse, if gravity predominates, or to expand, if the outward components of radiation pressure predominate.

\section{USE OF SNOWFLAKE REPLICAS FOR STUDYING WINTER STORMS}

\section{BY VINCENT J. SCHAEFER}

Research Laboratory, General Electric Company, N.Y.

A METHOD was described last winter by me $e^{1,2}$ A for making permanent replicas of snowflakes, ice crystals and other forms of evanescent objects.

The technique, in brief, is to cover the frozen object with a cold dilute solution of an appropriate resin dissolved in a suitable solvent. After the solvent evaporates, a very thin continuous film reproduces in intimate detail all the surface configurations of the specimen. The substance of the original object is then removed by sublimation or by melting and evaporating, after which the resin shell, which optically appears identical to the original object, may be photographed and studied at leisure. A $1-2$ per cent solution of polyvinyl formal ${ }^{3}$ dissolved in ethylene dichloride (1-2-dichloro thane) reproduces excellent replicas of snowflakes and other forms of frozen moisture.

For collecting snowflakes a piece of black velvet stretched on a board is used to eatch the specimens. A small drop of the resin solution is placed on a glass slide with a tapered rod. 'The rod, which still retains a small amount of the resin solution, is then immediately brought into light contact with the selected specimen and the flake readily adheres to it by surface tension. The specimen leaves the rod when it is brought into contact with the drop of liquid on the slide. All equipment is kept outdoors in a sheltered place throughout the winter.

Since the method of making permanent replicas is so simple, it would seem that those interested in winter weather phenomena might secure specimens from various types of storms for detailed study of these fascinating frozen forms in their possible relation to later meteorological occurrences. To illustrate these possibilities, the thirty-six photomicrographs reproduced herewith were obtained in a thirty-minute fall of large snow crystals at Schenectady, New York, U.S., during 7.00-7.30 a.m., March 12, 1941. During this short period, 150 specimens were collected and of these the 36 photomicrographs reproduced represent a typical cross-section of the replicas obtained. In securing these specimens the collecting board was cleaned every few minutes to make sure that representative crystals were secured throughout the fall. The photomierographs were all made at the same magnification, so that the change in size as well as form can readily be seen in the photograph.

The climatic conditions when the specimens were collected showed a falling barometer at $29 \cdot 70$ in., a temperature of $26^{\circ} \mathrm{F}$. with a north-west wind blowing. As happens frequently in this section of the United States, the crystal fall of large symmetrical crystals occurred at the close of a storm which deposited a total of about ten inches of snow. The snow of the storm contained a large amount of water $(0.09 \mathrm{in}$. water per inch of snow) so that we

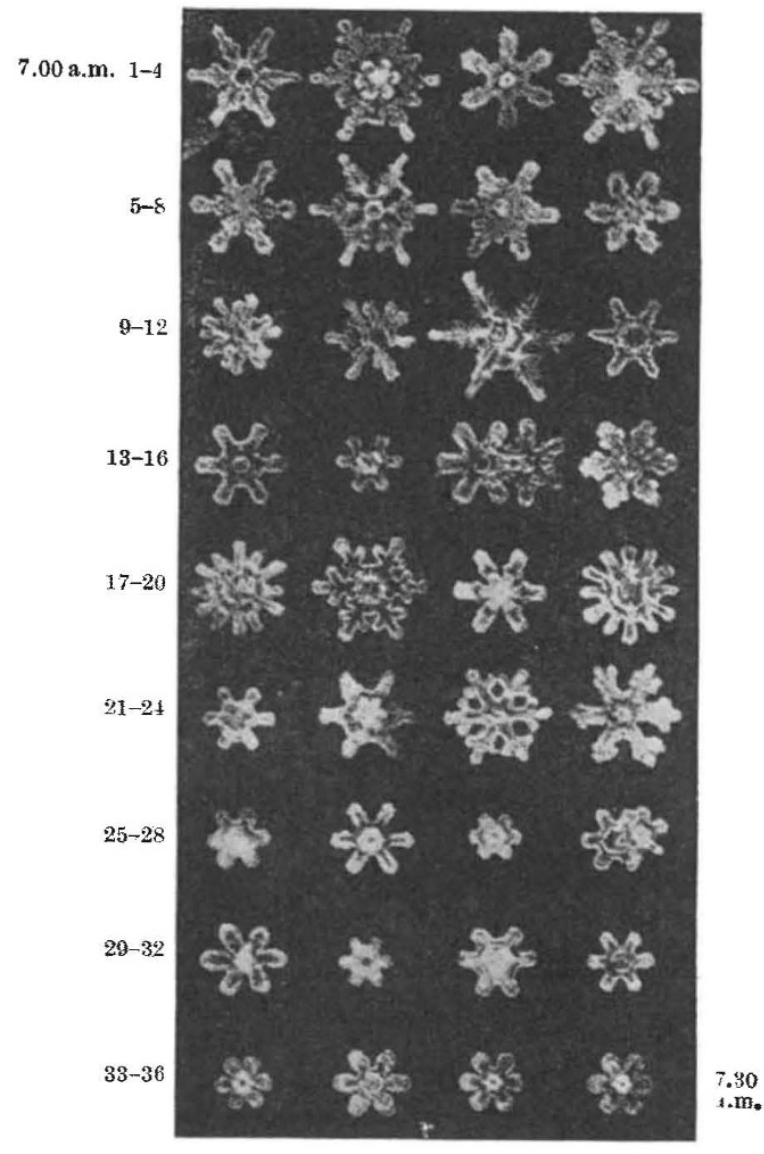

would term it a 'wet' snow. At 7.30, when I stopped collecting, the symmetrical crystals were replaced by the more common non-erystalline forms of assymetrical flakes which continued for several hours, after which the wind changed and the skies cleared. It will be noted that the crystals collected at the start of the fall had a considerable amount of secondary deposits which gradually disappeared as they decreased in size and changed in form.

Other forms of frozen precipitation such as sleet, graupel and ice crystals, terrestrial forms such as columnar and tabular frost, as well as breath patterns and crystals of low melting point such as benzene and acetic acid may all be prepared in replica form. by the method described.

1 Science, 98, 239 (1941).

Museum News, 19, No. 6, p. 11 (1941).

- Shawinigan Prod. Corp. Shawinigan Falls, Ontario, Canada. 